\title{
Nickel Steel in the Golden Arrow.
}

THE publications of the Bureau of Information on 1 Nickel of the Mond Nickel Co., Ltd., have from time to time provided most valuable information on many different aspects of the use of nickel in all types of metallurgical and engineering activity. Paper A, No. 4, recently issued, deals with the use of nickel steel in the Golden Arrow, in which Sir Henry Seagrave attained an average speed in two runs in opposite directions of 231.36 miles per hour.

The whole of the main and sub-frames of the Golden Arrow were made of a nickel steel containing 3.5 per cent of nickel and $0 \cdot 3$ per cent of carbon, and it is of interest to note that the side members, which were $19 \mathrm{ft} .6 \mathrm{in}$. long, were pressed in one length. The very extensive use of this steel, which incidentally was largely used in the brake equipment, indicates its dependability and the wide range of properties obtainable from it with different heat treatments. In the normalised condition it will give a tensile strength of 35 tons per square inch, together with 25 per cent elongation. A $1 \frac{1}{2}$ in. diameter bar oil-hardened from $840^{\circ} \mathrm{C}$. and tempered at $550^{\circ} \mathrm{C}$. gave a yield point of 42 tons per square inch, a maximum stress of 55 tons per square inch, an elongation of 25 per cent, a reduction of area of $6 \mathrm{l}$ per cent, and an impact figure of $56 \mathrm{ft} .1 \mathrm{~b}$.

For the main parts of the axles, where a particularly strong material was needed, a nickel-chrome-molybdenum steel of the following composition was chosen Carbon 0.3 per cent, manganese 0.4 per cent, nickel 3.5 per cent, chromium 0.65 per cent, molybdenum 0.2 per cent. This material, which was also used for the gears, gives in the heat-treated condition a yield point of 56 tons per square inch, a maximum stress of 63 tons per square inch, 20 per cent elongation, 60 per cent reduction of area, and an Izod value of $67 \mathrm{ft}$. $-1 \mathrm{lb}$. This steel gives exceptional uniform properties throughout its cross-section when properly heat-treated, which, no doubt, influenced the designer in his selection.

A 5 per cent nickel case-hardening steel containing about $0 \cdot 1$ per cent of carbon was extensively used for parts subject to considerable wear, such, for example, as the swivel-pins. Refined at $830^{\circ} \mathrm{C}$. and quenched from $760^{\circ} \mathrm{C}$., the approximate tensile figures given are: Maximum stress 55 tons per square inch, elongation 15 per cent, reduction of area 40 per cent, with an impact value of $20 \mathrm{ft}$.-lb. For several parts of the steering mechanism where the stresses involved may be exceptionally high, a nickel-chrome-molybdenum steel of the following composition was chosen : Carbon 0.25 per cent, manganese 0.5 per cent, nickel 3 per cent, chromium 1.2 per cent, molybdenum 0.2 per cent. In the quenched and tempered condition, the mechanical properties obtained from this steel are: Yield point 62.5 tons per square inch, maximum stress 69 tons per square inch, elongation 19.5 per cent, reduction of area 61.5 per cent, impact value $54 \mathrm{ft}$. $-\mathrm{lb}$.

For the clutch casing, cover plates, and certain small levers, a nickel-chrome steel was specified containing 0.3 per cent of carbon, 3.5 per cent of nickel, and 0.6 per cent of chromium. When hardened in oil from $830^{\circ} \mathrm{C}$. and tempered at $600^{\circ} \mathrm{C}$. the material gave : Yield point 49 tons per square inch, maximum stress 58 tons per square inch, elongation 22 per cent, reduction of area 55 per cent. For the clutch centre, withdrawal sleeve, and several other details, a high tensile case-hardening steel containing 3.5 per cent of nickel and I per cent of chromium was employed. After carburising, the steel was given two quenching treatments, one from $830^{\circ} \mathrm{C}$. and one from $770^{\circ} \mathrm{C}$., and afterwards tempered at $200^{\circ}$ to obtain a maximum toughness. The properties of this material in the form of a $1 \frac{1}{8}$ in. diameter bar were: Yield point 55 tons per square inch, maximum stress 69 tons per square inch, elongation 15 per cent, reduction of area 45 per cent, and impact value $28 \mathrm{ft}$.-lb.

It will be appreciated that, apart from the use of nickel steels, the construction of this machine would have been impossible.

\section{Investigations in Greenkeeping Problems.}

THE St. Ives Research Station, Bingley, Yorkshire, 1 which has been established by the British Golf Unions for the purpose of studying greenkeeping problems from the scientific aspect, has issued the first number of the Journal of the Board of Greenkeeping Research. The development and organisation of the scheme are explained in a foreword, and an interesting account is given by the Director, Mr. R. B. Dawson, of the surroundings and historical associations of the St. Ives estate. A general discussion follows of the kind of problems confronting the greenkeeper and the line of attack to be undertaken in their solution. The station has an ambitious programme, and useful work has already been accomplished.

It is realised that the present condition of a turf is largely due to its previous treatment, and that much valuable knowledge may be obtained by collecting and classifying existing information. All those interested are invited to contribute their experiences for this purpose. An advisory system is already active and a special feature of the Journal will be the publication of inquiries dealing with problems of general interest, together with their respective replies. Excellent examples of such correspondence are given in the first number.

The choice of site for the research station has been fortunate. There is a wide range of soils within the relatively small confines of the estate, and further, a difference in elevation from $300 \mathrm{ft}$. to $900 \mathrm{ft}$. is available. More than three acres of adjoining land have been acquired and some 400 plots are to be set up to determine the best conditions, both manurial and cultural, for the production of first-class putting greens, for comparative tests with selected seed mixtures, and for vegetative propagation trials of other grasses, notably Agrostis canina, which produces stolons. The use of stolon-forming grasses for lawns in India is the subject of a further article of interest.

Greenkeeping problems have changed considerably in recent years, owing largely to such alterations in practice as the use of compost in place of the heavy roller, and by the introduction of mowers of improved design and numerous chemical fertilisers. Hitherto, agricultural methods have usually been employed, and too often the supposition that what is suitable for pasture is equally good for the golf green has proved a fallacy. A special type of turf is required for greens, free from coarse grasses, weeds, and worm casts. For this purpose the effect of various fertiliser treatments will be determined and a thorough, unbiased investigation of the so-called acid theory, which maintains that the type of turf required is obtained under acid soil conditions, will also be undertaken. Consideration will be given to climatic, physiographic, edaphic, and biotic factors.

For the success of the work it is essential that the various golf clubs themselves should give their hearty co-operation and such financial support as they are able. Later, it is hoped to increase the scope of the work and to extend the investigations to the problems of turf culture peculiar to other sports.

No. 3140 , VoL. 125] 